\title{
Oficina de brinquedos e brincadeiras na promoção de comportamentos sociais
}

Workshop on toys and games promoting social behaviors

\section{Leys Eduardo dos Santos Soares}

Universidade Federal da Paraíba, Brasil, Brasil

leyseduardo@hotmail.com

Elizara Carolina Marin

Universidade Federal da Santa Maria, Brasil

elizaracarol@yahoo.com.br

\section{Pierre Normando Gomes-da-Silva}

Universidade Federal da Paraíba, Brasil

pierrenormandogomesdasilva@gmail.com

\section{Resumo:}

Este artigo apresenta a análise dos resultados de uma intervenção com a Oficina de Brinquedos e Brincadeiras (OBBA) no comportamento de crianças identificadas com condutas antissociais. Pesquisa de abordagem qualitativa, do tipo pesquisa-ação, realizada com uma turma do $5^{\circ}$ ano do Ensino Fundamental, numa escola pública de João Pessoa-PB. Os alunos foram identificados por meio de um roteiro de observação e avaliados, antes e durante a OBBA, pela Escala de Tendência Antissocial (ETA). Após período de implementação do projeto, em suas diferentes etapas (Apresentação, Avaliação, Implementação, Intervenção), evidenciou-se pela ETA um aumento significativo de açôes sociais de emprestar, oferecer, auxiliar, agradecer, elogiar e dialogar, naqueles com condutas antissociais.

PalaVras-chave: Jogo, Ensino, Psicanálise, Educação Física.

\section{ABstraCt:}

This article presents the analysis of the results of an intervention with Toys and Games Workshop (OBBA by its acronym in Portuguese) on the behavior of children identified with antisocial conducts. Qualitative approach research, research-action type, was carried out with a group of the 5th year of elementary school, in a public school in João Pessoa-PB. The students were identified through an observation script and evaluated, before and during the workshop, by the Anti-Social Trend Scale (ETA by its acronym in Portuguese). After implementing the project over a period of time, in its different stages (Presentation, Evaluation, Implementation, and Intervention), a significant increase in social actions such as lending, offering, assisting, thanking, praising and dialoguing in those with antisocial behavior was evidenced.

KeYwORDs: Game, Teaching, Psychoanalysis, Physical Education.

\section{INTRODUÇÃO}

No ambiente escolar é possível perceber uma série de comportamentos que levam professores e todo o corpo pedagógico a questionar os reais motivos de atitudes indisciplinadas e violentas que, muitas vezes, ocorrem sem motivo aparente entre os alunos. Diversos estudos reconhecem que problemas de agressões, violências e a falta de atitudes sociais são recorrentes tanto nas mais diversas escolas do Brasil quanto nas mais diferentes fases da Educação Básica (Abramovay, 2002; Abramovay \& Rua, 2002; Abramovay, Cunha \& Calaf, 2009).

Nesse contexto, os professores necessitam criar estratégias para conviver com estes alunos, a fim de desempenharem suas atividades. Todavia, por não compreenderem os motivos desses comportamentos, os esforços empreendidos, amiúde, não resultam em sucesso, o que contribui para desenvolverem quadros de estresse e irritação, prejudicial ao processo de ensino-aprendizagem, conforme apontado nas Diretrizes Curriculares Nacionais da Educação Básica (Brasil, 2013). 
Na busca de uma explicação do porquê da ocorrência dessas atitudes nas escolas, recorremos às formulações psicanalíticas de Winnicott $(1999 ; 2000 ; 2012)$, em que apresenta o conceito de "tendência antissocial" como um modo de comportamento assumido por alguns indivíduos, aos quais podem se manifestar com atos de agressões, destruição, desordem, envolvimento em brigas, discussões e roubos (e seu correlato, a mentira). Cabe esclarecer que qualquer criança em algum momento de sua vida pode se comportar antissocialmente, sem que isso seja necessariamente determinado por uma tendência. Para o autor, a "tendência antissocial" está relacionada com a repetição e/ou constância, assumindo, desse modo, um padrão similar.

De acordo com Winnicott (2000, p.406), a "tendência antissocial” está diretamente relacionada com "dificuldades inerentes ao desenvolvimento emocional”, originada por uma privação, isto é, pelo sofrimento do indivíduo e derivado de algum tipo de perda de algo bom, de uma experiência boa, ou de uma falha, pondo fim a um período em que havia uma estabilidade do ambiente e relação satisfatória com o meio. A privação acontece num período em que a criança já tem capacidade para se lembrar do ocorrido. Winnicott (2012, p.200) explica que "os sintomas antissociais são tentativas de recuperação ambiental e indicam esperança. Fracassam não por serem dirigidas de modo errado, mas porque a criança não tem consciência do que está acontecendo". Não obstante, o indivíduo com condutas antissociais responsabiliza o ambiente pela estabilidade que necessita e, mais precisamente, busca na sociedade aquilo que não teve ou foi perdido no meio familiar (Winnicott, 1982).

As crianças necessitam de estabilidade ambiental para que tenham sentimento de segurança, de modo que possam brincar e se relacionar. A tarefa do ambiente não é retaliar ou punir, mas corresponder às necessidades da criança. Por isso, "o tratamento da tendência antissocial não é a psicanálise, mas sim um manejo, uma forma de ir ao encontro do momento de esperança e de corresponder a ele", explica Winnicott (2000, p.409).

Esse manejo na forma de apresentar o ambiente para a criança requer, primeiramente, dos pais ou daqueles que atuam no processo educativo, tal como os professores, por exemplo, observar o comportamento infantil como exteriorização de necessidades internas, uma vez que a comunicação e um ambiente suficientemente bons, que deem sustentação e atendam às suas necessidades, podem levar as crianças a estabelecer novas relações e conseguir brincar.

Winnicott (1982) atribui relevância especial ao brincar na vida do indivíduo, pois, para ele, brincar é sinônimo de saúde:

$\mathrm{Na}$ criança individual em evolução de amadurecimento, surge outra alternativa à destruição muito importante. É a construção [...] É um dos mais importantes sintomas de saúde, numa criança, quando surge e se mantém a atividade lúdica construtiva. Trata-se de algo que não pode ser implantado, como implantada não pode ser, por exemplo, a confiança. Aparece, com o decorrer do tempo, como resultado da totalidade das experiências concretas da criança no ambiente fornecido pelos pais ou pelos que atuam como pais (Winnicott, 1982, p.267).

Diante da recomendação do próprio Winnicott sobre os benefícios da atividade lúdica para a saúde das crianças, sugerimos a Oficina de Brinquedos e Brincadeiras (OBBA), um programa didático da Pedagogia da Corporeidade (Gomes-da-Silva; 2012; 2015; 2016), que propõe o jogo como espaço-tempo privilegiado para a formação humana, ou seja, o jogo como meio de encaminhar a nós mesmos para o autoconhecimento. Brincar é uma forma de habitar o tempo, vivendo as circunstâncias com mais atenção a si mesmo e realizando seu potencial criativo na atuação. Gomes-da-Silva (2016, p.10) explicita que "a finalidade das experiências vividas no jogo é auxiliar os jogadores a reconfigurarem sua corporeidade", seu modo de viver no mundo.

Como concebe Gomes-da-Silva (2012), a corporeidade é a forma existencial que vamos assumindo no mundo. É a tendência dos nossos gestos. É a linguagem do nosso modo habitual de sentir, reagir e refletir as circunstâncias vividas. É a maneira costumeira de nos posicionarmos em relação às solicitações do entorno, ganhando contornos posturais, orgânicos e psíquicos. Portanto, corporeidade é uma configuração existencial, um desenho do viver, possível de ser transformado. Mesmo entendendo que os hábitos dificilmente mudam. Essa configuração vai sendo assumida por cada indivíduo, intercambiando com seu coletivo social, como sendo sua. 
Por isso, a Pedagogia da Corporeidade (PC), como uma metodologia de ensino para a educação física, toma o jogo como prática de linguagem capaz de reconfigurar existências. Isto é, a PC considera o jogo em sua produção de sentido, seja em relação ao contexto de sua organização histórico-social e econômico-cultural seja em relação aos aspectos biológicos e psíquicos que estão sendo vivenciados. De tal modo que nas situações lúdicas são investigados os efeitos emocionais, energéticos e lógicos produzidos naqueles que jogam.

O pressuposto é que o jogo, criado pelo homem/cultura, modifica seu próprio criador, na medida em que este o vivencia. As regras de funcionamento, as técnicas de execução, as emoções e os raciocínios desencadeados vão produzindo metamorfoses existenciais. A PC orienta-se para produzir corporeidades poetantes, pessoas mais criativas, responsáveis e conscientes de si próprias, portanto, brincantes para Gomesda-Silva (2015). O jogo aqui é tratado como situação em que se brinca, não diferenciando se está sendo jogada por criança ou idoso, se possui a seriedade esportiva ou da brincadeira infantil, se acontece na escola, no hospital ou no presídio. A situação lúdica é a categoria norteadora dessa proposição teórico-metodológica, por isso é abordado com implicações educacionais, terapêuticas e artísticas.

Nessa perspectiva, quando identificamos algum problema escolar, como é o caso da "tendência antissocial", compreendemos que por meio da proposição de jogos é possível reconfigurar o modo como as crianças convivem, ao favorecermos situações de movimento com ambiente seguro, gerador de confiança, para cada um realizar seu potencial criativo. Desse modo, lançamos mão de um dos programas didáticos que a PC apresenta, a Oficina de Brinquedos e Brincadeiras (Gomes-da-Silva, 2013).

Os jogos no programa da Oficina de Brinquedos e Brincadeiras (OBBA) têm como princípio a construção do próprio brinquedo a partir de materiais reutilizáveis e de baixo custo. A OBBA oferece 24 brinquedos de construção artesanal, sistematizados em termos de materiais necessários, passos para construção e brincadeiras realizáveis e habilidades aprendidas.

OBBA não é um programa acabado, com estrutura rígida; consiste, antes, numa proposição aberta a ser construída junto à comunidade escolar e se organiza a partir do princípio orientador desse gênero lúdicoConstrução, que é favorecer a noção de reversibilidade, envolvendo os processos de composição, montagem e fabricação. A finalidade é confrontar a noção linear e progressiva do tempo com a vivência das possibilidades de recomeçar e recriar o jogo, a circunstância e o próprio modo de se relacionar com o mundo.

Assim, diante dos impactos que a OBBA pode proporcionar para crianças com atitudes antissociais, buscamos investigar quais os efeitos da implementação dessa Oficina para o comportamento de crianças com "tendência antissocial" no Ensino Fundamental, numa escola pública.

\section{MÉtodos}

Realizamos este estudo por meio da abordagem qualitativa, por obter, como assinala Godoy (1995, p.58) "dados descritivos sobre pessoas, lugares e processos interativos pelo contato direto do pesquisador com a situação estudada, procurando compreender os fenômenos segundo a perspectiva dos sujeitos, ou seja, dos participantes da situação em estudo”.

Utilizamos como metodologia a pesquisa-ação, "concebida e realizada em estreita associação com uma ação ou com a resolução de um problema coletivo e no qual os pesquisadores e os participantes representativos da situação ou do problema estão envolvidos de modo cooperativo ou participativo" assinala Thiollent (1994, p.14). Envolve tanto identificar os problemas da situação alvo da pesquisa quanto propor ações com o intuito de transformá-la. Funda-se na interação entre pesquisadores e participantes envolvidos, donde resulta a ordem de prioridade dos problemas a serem pesquisados e as soluções a serem encaminhadas sob forma de ação concreta (Thiollent,1994).

Nesta perspectiva, a pesquisa-ação auxilia no desenvolvimento de alternativas para resolução dos problemas encontrados nas situações de aula. A partir do reconhecimento dos problemas causados pelas condutas antissociais, buscamos elaborar estratégias metodológicas com o objetivo de transformar a realidade 
encontrada durante as situações de aula. Este estudo foi autorizado pelo comitê de ética em pesquisa do Centro de Ciências da Saúde - Universidade Federal da Paraíba (protocolo nº 064/16).

\subsection{Sujeitos e Etapas da Pesquisa}

A pesquisa foi realizada com estudantes da turma do $5^{\circ}$ ano do Ensino Fundamental de uma Escola da rede pública de ensino do município de João Pessoa- $\mathrm{PB}$, localizada no bairro do Cristo Redentor, conhecido na cidade por seu histórico de violências. A execução da pesquisa orientou-se em quatro etapas:

1) "Apresentação". Apresentamos a proposta de pesquisa para o corpo de professores da escola, a fim de identificar interesse de realização e sugestões de turmas em que mais se observam comportamentos que poderiam ter relação com problemas derivados da "tendência antissocial".

2) “Avaliação". Após indicação dos professores, observamos aulas de uma turma do $5^{\circ}$ ano do ensino fundamental, com 24 alunos matriculados, com o fim de avaliar o comportamento social dos alunos. As observações foram guiadas por um roteiro de observação (quadro 1) com base em categorias analíticas, inspirado na Análise de Conteúdo (Bardin, 2011). Foram realizadas em três dias letivos de uma semana, durante todo o período da manhã. Nesses dias, observamos as aulas da professora de classe e do professor de Educação Física, totalizando 12 horas de observação. Todas as aulas foram filmadas e registradas no diário de campo. A partir dessas observações foi possível destacar cinco alunos desta turma com conduta antissocial.

QUADRO 1

Roteiro de observação da "tendência antissocial".

\begin{tabular}{|c|c|c|c|c|}
\hline \multirow{2}{*}{ Analítica } & Empírica & $\begin{array}{c}\text { Unidades de } \\
\text { contexto }\end{array}$ & $\begin{array}{c}\text { Unidades de } \\
\text { Registro I }\end{array}$ & $\begin{array}{c}\text { Unidades de } \\
\text { Registro II }\end{array}$ \\
\hline \multirow{3}{*}{$\begin{array}{c}\text { Tendência } \\
\text { Antissocial }\end{array}$} & \multirow{3}{*}{$\begin{array}{c}\text { Comportamento } \\
\text { Social }\end{array}$} & Solidarizar & Compartilhar & Emprestar \\
\cline { 5 - 5 } & & Ser gentil & \multirow{2}{*}{ Tratar bem } & Oferecer \\
\cline { 5 - 5 } & & & & Agradiar \\
\cline { 5 - 5 } & & & Elogiar \\
\hline
\end{tabular}

Fonte: elaboração dos professores-pesquisadores.

3) "Implementação". Dos 24 jogos do Programa OBBA (Gomes-da-Silva, 2013), foram apresentados aos alunos 08 (quadro 2), escolhidos pelos professores-pesquisadores por suas semelhanças de habilidades motoras, lógica de funcionamento e grau de complexidade na construção, seja em relação aos materiais envolvidos (mais ou menos materiais), seja em relação à construção, mais simples ou complexa. Para cada brinquedo foram planejadas aulas, uma mais voltada para a construção e outra mais para realização de brincadeiras. Desses jogos foram escolhidos quatro, por meio de votação, para serem vivenciados na OBBA: peteca, frescobol, bola de papel e pula-bola. 
QUADRO 2

Jogos do Programa OBBA apresentados à turma.

\begin{tabular}{|c|c|c|c|c|}
\hline $\begin{array}{c}\text { Habilidades } \\
\text { Motoras }\end{array}$ & $\begin{array}{c}\mathrm{N}^{\circ} \\
\text { aulas }\end{array}$ & Construção Simples & $\begin{array}{c}\mathrm{N}^{\circ} \\
\text { aulas }\end{array}$ & Construção Complexa \\
\hline Manipulativa: rebater & 01 & Peteca & 02 & Frescobol \\
\hline $\begin{array}{c}\text { Manipulativa: chutar } \\
\text { Locomotiva: saltar }\end{array}$ & 01 & $\begin{array}{c}\text { Futebol com bola de } \\
\text { papel }\end{array}$ & 02 & Pula-bola \\
\hline $\begin{array}{c}\text { Manipulativa: } \\
\text { impulsionar }\end{array}$ & 01 & Tampinha Cross & 02 & Futebol de pregos \\
\hline $\begin{array}{c}\text { Manipulativa: } \\
\text { arremessar }\end{array}$ & 01 & Acerte o alvo & 02 & Boliche de garrafas \\
\hline
\end{tabular}

Fonte: elaboração dos professores-pesquisadores.

4) "Intervenção". A intervenção ocorreu com os brinquedos eleitos, num total de 6 aulas, com duração de 1 h30 cada, totalizando, portanto, $13 \mathrm{~h} 30$ de intervenção; Sendo que para os brinquedos mais simples (Peteca e Bola de papel) foi destinada uma aula para cada, isto é, no mesmo dia foram realizadas a construção do brinquedo e as brincadeiras. Já para os brinquedos de construção mais complexa foram destinadas duas aulas, uma para a construção e outra para a vivência das brincadeiras. A intervenção aconteceu por meio de aulas realizadas a partir da estrutura da Aula Laboratório da Pedagogia da Corporeidade - ALPC (Gomes-da-Silva, 2016), estruturada em três momentos espiralados, interdependentes e complementares.

Primeiro, Sentir, momento inicial da aula. É o instante da sensibilização; funciona como um chamamento para o estar esperto no aqui e agora da aula. É um entrar em contato com as emoções, para o que o professor possibilita situações de movimento com músicas ou cantigas de rodas que tematizem a aula, criando um “ambiente de sedução, fascinação e encantamento" (Gomes-da-Silva, 2016, p.103). Nas aulas da OBBA foram proporcionadas situações de alegria e animação por meio da realização de cantigas de rodas, que falavam sobre o brinquedo, e das quais o professor-pesquisador participava conjuntamente aos alunos;

Segundo, Reagir, momento de apresentação das situações desafiadoras de movimento. Funciona como um chamamento à atenção ao contexto da atividade, a problemática do jogo e as capacidades físico-motoras e habilidades cognitivas para resolução. O desafio é reagir a situações inacabadas, que provocam uma reação dos participantes; eles partem do já sabido e necessitam de uma nova ação para encontrar a resolução. $O$ professor levanta um problema e mobiliza o grupo para solucioná-lo, tendo por objetivo ativar novas experiências, a fim de despertar novas perspectivas de ver e se situar no jogo (Gomes-da-Silva, 2016). Durante as aulas da OBBA, esse momento da aula foi subdividido em duas situações didáticas: primeira, "construir seu brinquedo", e, segunda, a "experimentação das brincadeiras".

Terceiro, Refletir, momento final da aula. Um chamamento a fazer do vivido uma experiência interior. Sentados em círculo, o professor propõe uma situação de representação do vivido, seja com desenhos, pinturas ou modelagens, contanto que represente o que aprendeu. Um modo de facilitar o acesso dos alunos a si mesmos, entrarem em contato com o que os marcou na vivência para, em seguida, verbalizarem sua representação, numa forma de acesso à consciência individual, longe do linguajeiro repetido por todos (Gomes-da-Silva, 2016).

Essa tríade de produção de sentido (Sentir, Reagir e Refletir) possui ênfase em momentos específicos, mas acontece em interação contínua e oscilante em todos os instantes da aula. 


\subsection{Procedimento para Construção dos Brinquedos}

Para a construção dos brinquedos, reunimos os materiais necessários, coletados pelos alunos, sucedido da confecção seguindo o "passo a passo", descritos no Programa OBBA. Para construção da peteca: amassar 15 folhas de papel, no formato de uma bola e colocar no fundo de duas sacolas plásticas pequenas, uma revestindo a outra, a fim de formar a base. Com a extensão restante da sacola, acima da bolinha, realizar torções e, em sua base, enrolar fita adesiva para prender a bola dentro do revestimento. Cortar a parte acima da torção, deixando apenas um espaço de sacola, que simboliza as penas de uma peteca. Para colorir a peteca conforme o desejo individual, utilizamos lápis hidrocor. Para o frescobol, propomos desenhar a raquete numa capa dura de caderno, do tipo espiral grande, seguido pelo recorte do contorno com tesoura. No molde, colamos em ambos os lados folhas de papel oficio ou outro papel em cor, e o cabo da raquete revestimos com fita adesiva. A bolinha utilizada no jogo foi retirada dos frascos de desodorante roll on. Para o futebol com bola de papel, amassamos 15 folhas de caderno, cada uma no formato de uma bola, que passava a ser envolvida em outra folha, também amassada até completar as 15 camadas. Por fim, revestimos com fita adesiva, formando uma última camada da bola. Para o pula-bola, utilizamos o mesmo princípio de construção da bola exposto anteriormente. Amarramos a bola numa das extremidades de um cordão de nylon de, aproximadamente, 1 metro, e na outra extremidade construímos uma alça com tamanho que permitisse colocar o pé e ficar ajustado no tornozelo. Bola, cordão e alça eram coloridos com fita adesiva em cores.

A construção foi realizada em pequenos grupos, com até quatro integrantes, os quais tinham à disposição materiais e o passo a passo da construção. O objetivo era se ajudarem mutuamente, compartilhando materiais e aprendizagens, para que cada componente construísse seu próprio brinquedo. Na sequência, iniciava-se o momento de experimentação do brinquedo, com vivências de brincadeiras sugeridas pelo próprio grupo e experienciadas por todos.

\subsection{Instrumento de Avaliação}

Os resultados da OBBA foram avaliados a partir de uma escala de avaliação, denominada Escala de Tendência Antissocial (ETA), construída pelos professores-pesquisadores a partir dos indicadores elencados no roteiro de observação (Quadro 1). A ETA permitiu avaliar o comportamento social dos alunos antes e durante a realização da OBBA. Foram duas avaliações, integralmente filmadas, a primeira (ETA I), durante a Etapa 2 (Avaliação), e a segunda (ETA II), durante a Etapa 4 (Intervenção). Por essa escala de avaliação, as ações elencadas na categoria (Unidades de Registro II) receberam os seguintes valores: "0", para quando a ação indicada não houvesse sido observada; "1", para quando a ação fosse observada algumas vezes, e "2", para quando fosse observada muitas vezes.

\subsection{Análise dos dados}

A partir dos resultados evidenciados na ETA, analisamos os dados a partir do enfoque qualitativo, devido a necessidade de se verificar como o fenômeno da tendência antissocial se manifesta e se reproduz no ambiente escolar. Nesse sentido buscaremos analisar a situação de movimento como um todo e para além de variáveis isoladas. Concordamos com Godoy (1995, p.63) ao expressar sobre a impossibilidade de "compreender o comportamento humano sem a compreensão do quadro referencial (estrutura) dentro do qual os indivíduos interpretam seus pensamentos, sentimentos e ações”. A partir da análise qualitativa dos dados será possível compreender as alterações de comportamento entre antes e durante o desenvolvimento da oficina, de maneira que será possível evidenciar os impactos das metodologias ALPC e OBBA na transformação das relações estabelecidas durante as situações de aula. 


\section{Resultados e discussão}

$\mathrm{Na}$ educação escolar, a sociabilidade tem a ver com a interação entre os indivíduos por meio de atitudes embasadas no respeito ao outro e na cooperação, agindo de maneira colaborativa, em benefício do social. Seja na escola ou fora dela, a sociabilidade é um fundamento essencial do conviver humano (Freire, 1994; 2007). As aulas de educação física, com a implementação do Programa OBBA, partiram desse pressuposto e ofereceram um espaço-tempo lúdico com possibilidades de desenvolver as interações sociais. As noções de compartilhar, tratar bem e zelar pelo patrimônio estiveram presentes desde a construção do brinquedo até a realização das brincadeiras.

Na primeira avaliação ETA I, na categoria “solidarizar” (Quadro 3), só o indicador de compartilhamento 'auxiliar' foi pontuado, recebendo valor 1 , já que essa ação aconteceu algumas vezes. Na avaliação ETA II houve um aumento significativo, o valor passou para 2, visto que foi uma ação observada com frequência, especialmente no momento da construção dos brinquedos.

QUADRO 3

Categorias da Escala de Tendência Antissocial antes e durante a OBBA

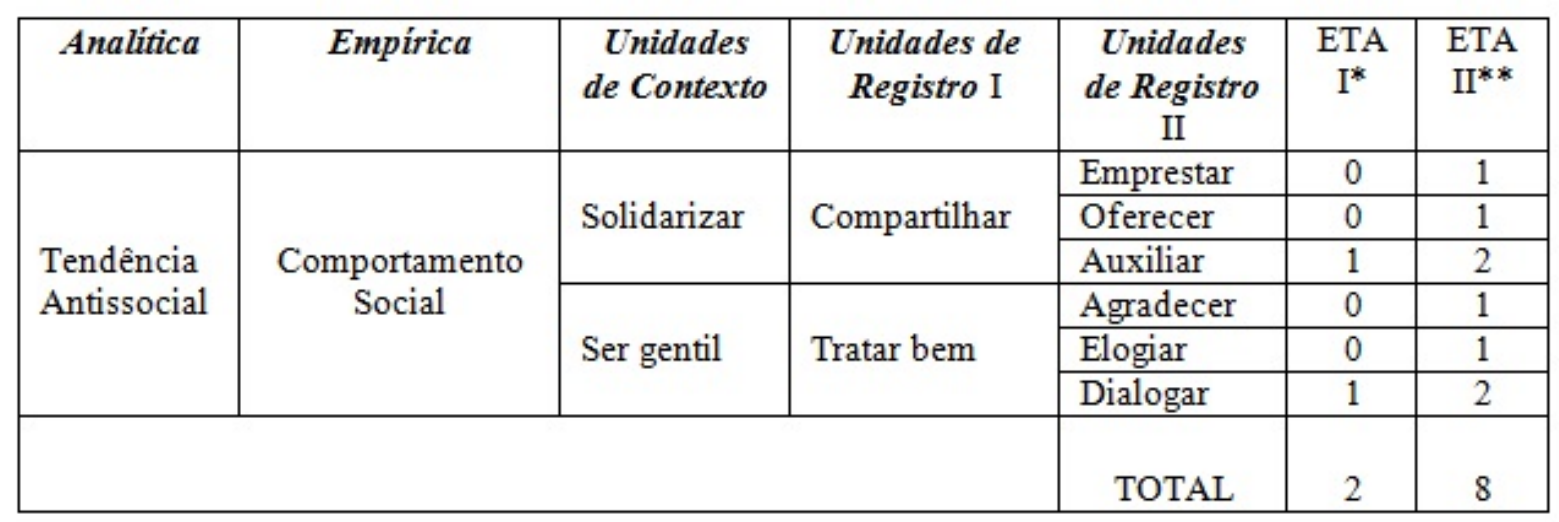

*ETA I - Primeira avaliação durante a Etapa Avaliação

** ETA II - Segunda avaliação durante a Etapa Intervenção

Fonte: elaboração dos professores-pesquisadores.

De acordo com Mattos (2010), auxiliar significa prestar ajuda a quem está com algum tipo de dificuldade. Observamos que, durante o momento de construção, quando algumas das crianças não estavam fazendo corretamente a peteca, outros as auxiliavam na tarefa. Por exemplo, as meninas solicitavam auxílio dos meninos e do professor para amassarem o papel para chegar ao formato achatado da base da peteca, pois demandava mais força. Assim também aconteceu na construção da raquete no frescobol, em que os meninos tinham dificuldades em colar frente e verso os papéis coloridos e pediram auxílio.

Nos pequenos grupos não havia crianças construindo sozinhas seus brinquedos, estavam sempre perto umas das outras, fosse observando ou dialogando sobre as construções. O Quadro 3 evidencia que não houve a ação 'emprestar' na primeira avaliação, recebendo valor 0. Contudo, durante a OBBA, essa ação foi constatada algumas vezes e foi pontuada com valor 1 . O aumento dessas ações de auxiliar e emprestar tem relação com a situação criada em disponibilizar materiais no grupo, mesmo sendo a construção individual. Não havia, por exemplo, uma tesoura para cada criança, mas uma para o grupo; por isso, enquanto um colega cortava o papelão para fazer a raquete, o outro tinha que esperar sua vez.

Essa situação possibilitou aos participantes do grupo o exercício de esperar o tempo do outro e se controlar no aguardo da sua vez, o que representou um aprendizado importante. Cada criança começou a perceber as dificuldades, suas e dos demais, para fazer os brinquedos. A disponibilidade de material no pequeno grupo, 
as trocas, empréstimos ou orientações exigiu que o aluno, mesmo aquele com condutas antissociais, tivesse empatia para com o outro, pois o fez esperar, observar e aprender com os erros ou acertos dos colegas.

Essa estratégia criou uma área de comunicação que favoreceu as trocas entre os alunos. Gomes-da-Silva (2016) acredita que a tarefa dos educadores, principalmente aqueles que trabalham com o jogo, é oferecer um "ambiente semiotizado", isto é, um ambiente que exija dos participantes a comunicação, a multiplicação de signos, por meio de trocas com objetos, diálogos corporais e conversações provocativas. Em nosso caso, isso aconteceu com os empréstimos de materiais e com o auxílio nas construções. Gomes-da-Silva (2015, p.21) defende "que esse ambiente comunicativo constitui o sujeito. Não só amplifica seus aparelhos perceptivos, ao captar, interpretar e comunicar mensagens, mas também modula afetos, que, por sua vez, coordenam as ações na circunstância".

Desse modo, o ambiente proposto nos pequenos grupos na OBBA, com as ações de emprestar e auxiliar, modelou o modo de os alunos se relacionarem. Favoreceu aos alunos com condutas antissociais se sentirem tranquilos, acolhidos e seguros. Como assinala Winnicott (2000, p.416), o "fornecimento de um ambiente que cuida”, que oferece estabilidade, pode apresentar uma nova chance de relação consigo e com o ambiente, especialmente quando a origem do comportamento antissocial for uma "falha ambiental na área de auxílio do ego e proteção em estágio de dependência individual” (Winnicott, 1983, p.186).

Vimos que a ação de 'oferecer' não esteve presente na ETA I; porém, durante a OBBA, ela passou a acontecer algumas vezes, especialmente nos momentos de construção. Cada grupo tinha a seu dispor materiais de decoração, como fitas coloridas e lápis de pintar, distribuídos em poucas unidades, de maneira que alguns grupos tinham determinadas cores, e outros, não, o que impelia as crianças a decorarem seus brinquedos, a saírem de seu grupo e solicitarem empréstimo de material a outro grupo. Algumas vezes, os materiais foram voluntariamente oferecidos pelas crianças, por exemplo, quando saíam de seu grupo e rodeavam outro para pedir algo, alguns procuravam saber o que necessitavam e cediam o material.

Essas interações modelaram emoções devido ao que Gomes-da-Silva (2014, p.23) denomina "zona de corporeidade”, quando uma situação de movimento exige do praticante uma semiotização espacial, interpretação sensível do entorno e uma modelação de subjetividade. Essa zona foi criada pelo espaço do compartilhar materiais, movido pela intenção do brincar livre. Nessa zona, as crianças com condutas antissociais ressignificaram a convivência: os pedidos, o oferecimento e, finalmente, a ação de auxiliar. Por isso, ressalta Gomes-da-Silva (2014, p.27), "é preferível que o professor invista na ambientação de suas aulas, organizando as situações de movimento para que haja semiotização e consequente subjetivação da aprendizagem desejada".

Ao comparar as duas avaliações na categoria 'solidarizar', observamos o aumento desta durante a Etapa 4 (Intervenção), nos diversos momentos das brincadeiras. Por exemplo, foi observado na brincadeira de peteca em duplas as crianças trocando passes com um mesmo objeto construído, não importando mais a quem pertencia a peteca, antes os dois compartilhavam em colaboração mútua. Nesse sentido, não apenas durante a construção do brinquedo, mas na própria atividade, foram observadas atitudes de sociabilidade se tornando mais presentes. Seja emprestando, oferecendo, auxiliando ou solidarizando as crianças passaram a uma conduta mais característica do compartilhar em benefício de um conviver mais saudável.

Os resultados alcançados assinalam que o ambiente escolar pode favorecer o processo maturativo e "curativo" dos alunos. Todavia, adverte Winnicott (1983, p.187), "a provisão ambiental deve ser suficientemente 'boa' para que a maturação se torne um fato no caso de cada criança”.

Observamos, como ilustra o Quadro 3, que a atitude de "Ser gentil", envolvendo ações de agradecer e elogiar, não esteve presente na primeira avaliação, por isso a atribuição do valor "0"; apenas o indicador "dialogar" recebeu valor "1". No entanto, esse resultado muda durante a Intervenção da OBBA, visto que "agradecer" e "elogiar" se fizeram presentes, recebendo o valor "1", e "dialogar" recebeu valor máximo, por ter sido uma atitude recorrente na oficina. 
Como já comentado anteriormente, o deslocamento das crianças - movidas pelo desejo e necessidade estética de colorir o seu brinquedo - entre os grupos para pedir emprestados materiais de decoração mobilizou aproximação, diálogos e gestos de agradecimento.

O "agradecer" e o "elogiar" aconteceu exclusivamente durante a OBBA e principalmente nesses momentos de empréstimos e trocas de materiais. Percebemos que o "agradecer" produziu alterações no convívio social, no que tange à reciprocidade e à tolerância de uns para com os outros. O "elogiar" se apresentou especialmente nos momentos em que crianças tinham mais dificuldades de fabricação da raquete, por exemplo, e passavam a elogiar seus pares nas estratégias que utilizavam.

A partir do aumento das atitudes de "agradecer" e "elogiar", observamos um agir mais gentil e frequente durante as brincadeiras, como, por exemplo, no frescobol, em que as meninas, inicialmente, tiveram mais dificuldades em acertar a bolinha com a raquete e o jogo perdia a cadência. Ao perceberem essas dificuldades, as crianças, inclusive aquelas identificadas com condutas antissociais, começaram a rebater na bolinha com menos força e, algumas vezes, deixando-a dar um toque no chão antes de chegar ao companheiro. Elas perceberam que a "gentileza" no jogar frescobol permitia a continuidade do jogo e passaram a adaptar seus movimentos às limitações de seus companheiros, num agir gentil, oferecendo ao colega a chance de rever suas ações, tais como: posicionamento, modo de segurar a raquete, força empreendida na rebatida e coordenação da ação.

Esses exemplos revelam como os alunos, mesmo aqueles com conduta antissocial, tiveram a oportunidade de integrar sua agressividade e dosá-la para que o jogo pudesse acontecer. Na perspectiva de Winnicott (1999), a criança, ao desempenhar essa função, foi capaz de integrar seus impulsos agressivos na experiência de brincar. Significa dizer que a criança com "tendência antissocial", ao reconhecer as limitações do colega, passou a perceber o outro de maneira diferente, passou a preocupar-se e a valorizá-lo.

Sanmartín (2005) destaca que existe no jogo um importante papel de socialização, e nos jogos em que se exige a participação do outro, o socializar-se é um aspecto inerente a sua prática, visto que os sujeitos estão sempre na dependência dos outros para que a atividade possa ocorrer. No decorrer das atividades da OBBA, constamos crescimento no desenvolvimento social das crianças, pois estavam mais atentas à presença dos demais colegas, agradecendo pelas gentilezas e valorizando o trabalho das demais. No exemplo do jogo de frescobol, foi observado que quando as meninas passaram a fazer os movimentos no frescobol com mais destreza e foram acertando com mais frequência, os colegas elogiaram sua evolução e ofereciam dicas para que batessem na bola de forma mais adequada. Assim, a lógica interna do frescobol possibilitou o exercício de ser gentil, ao reconhecer as limitações do outro e não excluí-lo da atividade, ao contrário, buscando meios para que o jogo continuasse. Tanto o frescobol quanto a peteca foram jogos que exigiam dos brincantes um ajuste de ação na interdependência do outro, visto que o modo de agir de um permitia ou impossibilitava a participação do outro. Vale destacar que foi o próprio funcionamento do jogo que exigia uma determinada conduta social, sem a interferência do professor.

Como destaca o quadro 3, apenas o "dialogar" recebeu o valor máximo na segunda avaliação, porque foi uma ação presente tanto nas construções dos brinquedos quanto durante as brincadeiras. Uma das situações de movimento que mais promoveu trocas de diálogos foi durante a aula de "futebol com bola de papel", especialmente durante a brincadeira de "travinha em duplas". Nessa brincadeira foram formadas duas equipes, cada qual com seis jogadores, sendo que cada equipe formava duplas, e esses jogadores não podiam soltar as mãos durante o jogo. Assim, eram constantes os diálogos entre participantes, negociando com sua dupla quais movimentos deveriam fazer, seja para os passes ou mesmo os chutes a gol.

Tanto nos momentos de construção quanto durante as brincadeiras foi possível notar diálogos das crianças sobre as estratégias elaboradas durante as construções e brincadeiras. Não se tratava de conversas paralelas que, antes da OBBA, dificultavam o andamento da aula, mas de diálogos que aconteciam várias vezes nos grupos de construção, com o intuito de melhor manejar os objetos. Com as atividades da OBBA, as crianças não só 
passaram a adotar atitudes de gentilezas, mas, outrossim, a dialogar, levando em consideração os objetivos da aula.

\section{Considerações FINAIS}

Os resultados apontam que, durante as aulas, a provisão ambiental facultada pelos grupos de construção com os decorrentes desafios propiciados pela OBBA - foi capaz de integrar o comportamento antissocial dos alunos para saber conviver com os demais, inclusive mais favoráveis ao surgimento de atitudes sociais, se comparado com momento da vivência das brincadeiras. As brincadeiras elaboradas mudaram a forma de agir dos alunos para brincar com os outros, já que foram gentis e adaptaram seus movimentos. Do total de ações de emprestar, oferecer, auxiliar, agradecer, elogiar e dialogar, em cada avaliação - antes e durante a OBBA -, houve uma ampliação de 2 para 8, ou seja, a oficina proporcionou um aumento de mais de $100 \%$ de realização de ações sociais.

Significa dizer que a escola pode ser um ambiente mobilizador de uma nova oportunidade de socialização e ressignificação do ser do aluno, principalmente se entendermos, à luz de Winnicott (1983; 1999; 2000; 2012), que a conduta antissocial se manifesta como esperança de que o meio tome conhecimento e compense a perda e/ou falha sentida no processo de maturação.

Sobremaneira, no âmbito das atitudes sociais, quando a criança é estimulada à sociabilidade num ambiente suficientemente adequado, favorece ao reconhecimento do outro e de si mesma, como uma pessoa que tem direitos, necessidades e dores (e não como objeto); a ver a presença do outro como imprescindível - no nosso caso, para que o jogo aconteça -, com suas capacidades e limitações; em síntese, favorece aos sentimentos de cuidado e de amor, fundamentais para qualquer processo educativo.

Para tal, propiciar situações de movimento, em que os alunos se organizem, no intuito de superar obstáculos e dificuldades, compartilhando saberes e dialogando sobre aprendizagens para alcançar os objetivos, apresenta-se como um caminho para uma maior presença de ações sociais no ambiente escolar, para viabilizar experiências internas e externas, ampliando a capacidade de reelaborar o seu ser, a realidade compartilhada e de enxergar o mundo.

\section{REFERENCIAS}

Abramovay, M. (2002). Escola e violência. Brasília: UNESCO.

Abramovay, M., Cunha, A. L., Calaf, P. P. (2009). Revelando tramas, descobrindo segredos: violência e convivência nas escolas. Brasília: RITLA, SEEDEF.

Abramovay, M., \& Rua, M. G. (2002). Violências nas escolas. Brasília: UNESCO.

Bardin, L. (2011). Análise de conteúdo. São Paulo: Edições 70.

Brasil. (2013). Diretrizes Curriculares Nacionais da Educação Básica. Brasília: Ministério da Educação.

Freire, J. B. (1994). Educação de corpo inteiro: teoria e prática da Educação Física. São Paulo: Scipione.

Freire, J. B. (2007). Conviver e aprender. En: Gomes-da-Silva, P. N., \& Caminha, I. O. (Coords.). Aprender a conviver: um enigma para a Educação. (pp. 49-64). João Pessoa: Editora Universitária UFPB.

Godoy, A. S. (1995). Introdução a pesquisa qualitativa e suas possibilidades. Revista de Administração de Empresas, 35(2), 57-63.

Gomes-da-Silva, P. N. (2016). Educação física pela pedagogia da corporeidade: um convite ao brincar. Curitiba, PR: CRV.

Gomes-da-Silva, P. N. (2013). Oficina de brinquedos e brincadeiras. Petrópolis, RJ: Vozes.

Gomes-da-Silva, P. N. (2015). Semiótica dos jogos infantis. João Pessoa: Ed. Universitária da UFPB.

Gomes-da-Silva, P. N. (2014). Pedagogia da corporeidade: o decifrar e o subjetivar na educação. Tempos e espaços em Educação, 7(13), 15-30. 
Gomes-da-Silva, P. N. (2012). A corporeidade do movimento: por uma análise existencial das práticas corporais. En: Hermida, J. F., \& Zoboli, F. (Coord.). Corporeidade e educação. João Pessoa: Editora Universitária da UFPB.

Mattos, G. (2010). Dicionário júnior da lingua portuguesa. São Paulo: FTD.

Sanmartín, M. G. (2005). Aprendizagens de valores sociais através do jogo. En: Murcia, J. A. M. (Coord.). Aprendizagem através do jogo. Porto Alegre: Artmed.

Thiollent, M. (1994). Metodologia da pesquisa-ação. (6ª ed.) São Paulo: Cortez.

Winnicott, D. W. (1999). Tudo comę̧a em casa. (3a ed.). São Paulo: Martins Fontes.

Winnicott, D. W. (1982). A criança e o seu mundo. (6a ed.). Rio de Janeiro: LTC.

Winnicott, D. W. (2012). Privação e delinquência. (5ª ed.). São Paulo: Martins Fontes.

Winnicott, D. W. (1975). O brincar e a realidade. Rio de Janeiro: Imago.

Winnicott, D. W. (2000). Da Pediatria à Psicanálise: obras escolbidas. Rio de Janeiro: Imago.

Winnicott, D. W. (1983). O ambiente e os processos de maturação: estudos sobre a teoria do desenvolvimento emocional. Porto Alegre: Artmed. 